\title{
The Incidence of Vaso-vagal Reactions Among Whole Blood Donors During Or Immediately After Donation
}

\author{
Atiar Rahman', Jolly Biswas², Md. Ashadul Islam³, Ayesha Khatun³, Nittyananda Shili ${ }^{3}$, Sheikh Saiful Islam Shaheen ${ }^{4}$, \\ Zillur Rahman Bhuiyan ${ }^{5}$ \\ ${ }^{1}$ Medical Officer, ${ }^{2}$ Chairperson, ${ }^{3}$ Assoc. Professor, ${ }^{4}$ Program Officer, Dept. of Transfusion Medicine Bangabandhu Sheikh Mujib Medical \\ University, Dhaka, Bangladesh, ${ }^{5}$ Senior Consultant \& Deputy Registrar, Bangabandhu Sheikh Mujib Medical University, Dhaka, Bangladesh.
}

\begin{abstract}
:
Background: The incidence of vaso vagal reaction among the whole blood donors are common. Few percent of these reaction may progress to syncope. Objectives: To evaluate the incidence of vaso-vagal reaction (VVR) among whole blood donors. Methods: This prospective, observational study was done in the department of transfusion medicine in Bangabandhu Sheikh Mujib Medical University from 01-04-2008 to 31-03-2009. Total 19553 blood donors were observed for vaso-vagal reaction. Results: The incidence of vaso-vagal reaction was $0.37 \%$, in male $0.33 \%$ and in female it was $0.67 \%$. Female donors were significantly more prone to develop vasovagal reaction ( $\mathrm{p}=0.001$ ). $78.8 \%$ of donors were first time donor and $28.8 \%$ were repeat donor. The clinical character of the symptoms according to frequency was- Sweating (86.3\%), Nausea/ Vomiting (80.8\%), Pallor (67.1\%), Dizziness (39.7\%), Loss of consciousness and fainting, increased rate of respiration (30.1\%), anxiety presented (16.4\%) and vertigo (1.4\%). Conclusion: Although the incidence of vasovagal reactions in our study is lower than other studies, it is important to follow strict donor selection criteria and ensure careful monitoring during and immediate after the donation process to avoid the fatal consequences.
\end{abstract}

Key words: Vaso-vagal reaction, donor reaction, blood donation.

[BSMMU J 2011; 4(2):106-109]

\section{Introduction:}

The unremitting need and increasing demand for blood components constantly challenges blood centers to maintain a safe and adequate blood supply from a decreasing pool of eligible donors ${ }^{1}$. South East Asia account for $25 \%$ of the world's population but collects only $9 \%$ of the world's blood supply as a result 7 million units of blood in a year, but there is need of a total 15 million units of blood ${ }^{2}$. In Bangladesh the annual demand for blood transfusion is estimated to be 2,00,000 to 2,50,000 unit per year. But due to lack of voluntary donor and consciousness among people this demand is hardly met ${ }^{3}$. Because blood donors are altruistic volunteers, they should be protected as much as possible from adverse reactions. As among repeat donors adverse reactions are associated with decreased intentions to donate in future ${ }^{4}$.

Blood donors normally tolerate the donation very well, but occasionally adverse reactions of variable severity may occur during or at the end of the collection. In most cases, systemic reactions are seen as vaso-vagal reactions that can be triggered by the pain of the venipuncture, by the donor seeing his or her own blood, by the donor seeing another donor unwell, by the anxiety and state of tension of undergoing the donation, etc ${ }^{5}$.

Address for Correspondence: Dr. Atiar Rahman, Medical Officer, Dept. of Transfusion Medicine Bangabandhu Sheikh Mujib Medical University, Dhaka, Bangladesh,
Vaso-vagal reactions occur in 2 to 3 percent of blood donors and 0.08 to 0.34 percent of these reactions progress to syncope ${ }^{6}$. A decrease in circulating blood volume and an imbalance in autonomic nerve activity inducing bradycardia, hypotension and peripheral ischemia are considered to be causes of VVR during and immediate after whole blood donation ${ }^{7}$. Sudden syncope is clinically significant, because the donor may suffer trauma during the fall. Such traumas sometimes lead to significant injuries, including lacerations, concussions, and, very rarely, bone fractures ${ }^{8}$.

Present study was aimed to explore the incidence of vasovagal reaction among the whole blood donors and to find of the most common cause of VVR. This is an original work for the first time in BSMMU.

\section{Methods:}

This prospective, observational study has done in the department of transfusion medicine in Bangabandhu Sheikh Mujib Medical University from 01-04-2008 to 3103-2009. During the study period total 19553 blood donors of ages 18-60 years of both sexes are included and subjects with body weight $<50 \mathrm{~kg}$, Pluse rate $<50$ and $>100$, Blood pressure $>180 / 110 \mathrm{~mm}$ of $\mathrm{Hg}$, Hb level $<12.5$ gm were excluded.

Blood donors' serial number, the date of blood collection and other characteristics were recorded. Every case of a 
donor reaction before, during or 30 min after the blood donation was recorded on a Donor Reaction Report Form. This standardized form includes the biological characteristics of the donor, the symptoms of the adverse reaction and if the donor was sleepless tired or stressed before blood donation and any donor concealed this situation during the medical interview and examination. The responsible physician who examined the donor fills in the report form and asks the donor about sleeplessness, tiredness or stress. The scale is 'a little tired or stressed' and 'very tired or stressed' (the latter donors are excluded from blood donation). Concerning sleeplessness, the limit is less than $5 \mathrm{~h}$ of sleeping last night. All the necessary information and clinical data was systematically recorded in a pre-designed data collection sheet.

Table-I

Distribution of vaso-vagal reaction by sex and history of previous donation among the whole blood donors.

Distribution of vaso-vagal reaction of among whole blood donors

\begin{tabular}{lccc}
\hline Total donor & Frequency of VVR & \multicolumn{2}{c}{ Percent } \\
\hline 19553 & 73 & 0.37 & $95 \%$ CI \\
& & & $0.28-0.46$ \\
\hline
\end{tabular}

Distribution of vaso-vagal reaction by sex.

\begin{tabular}{lcccc}
\hline Sex & $\begin{array}{c}\text { Total } \\
\text { donor }\end{array}$ & $\begin{array}{c}\text { Frequency } \\
\text { of VVR }\end{array}$ & Percent & $\begin{array}{c}\mathrm{P} \\
\text { value }\end{array}$ \\
\hline Male & 17168 & 57 & 0.33 & 0.011 \\
Female & 2385 & 16 & 0.67 & \\
\hline
\end{tabular}

Distribution of vaso-vagal reaction by history of previous donation.

\begin{tabular}{lcccc}
\hline $\begin{array}{l}\text { Previous } \\
\text { Donation }\end{array}$ & $\begin{array}{c}\text { Total } \\
\text { donor }\end{array}$ & $\begin{array}{c}\text { Frequency } \\
\text { of VVR }\end{array}$ & Percent & $\begin{array}{c}\text { P } \\
\text { value }\end{array}$ \\
\hline Yes & 11145 & 21 & 0.19 & 0.001 \\
No & 8408 & 52 & 0.62 & \\
\hline
\end{tabular}

Table-II

Characters of donors with VVR

Distribution by history of previous attacks

\begin{tabular}{lcc}
\hline Yes & 5 & 6.8 \\
No & 68 & 93.2 \\
\hline Total VVR & 73 & 100 \\
\hline Distribution by light meal & 4 hours before donation: \\
\hline Yes & 61 & 83.6 \\
No & 12 & 16.4 \\
\hline Total & 73 & 100.0 \\
\hline
\end{tabular}

Statistical analyses of the results were obtained by using window based computer software devised with Statistical Packages for Social Sciences (SPSS-15) Version-15.0. Statistical significance was set at $\mathrm{p}<0.05$ and confidence interval was set at $95 \%$ level. Data was analysed by Chisquare test.

\section{Results:}

The study was conducted over 19553 whole blood donors, among them 73 were found to be suffered with Vaso-vagal reaction with an incidence of $0.37 \%$. The mean age was $27.63 \pm 6.29$ years, ranging from 18 to 40 years. Male: Female $=3.56: 1$, incidence of VVR in male donors was $0.33 \%$ and in female was $0.67 \%(p=0.011) .0 .19 \%$ were first time donor and $0.62 \%$ were regular donor $(\mathrm{p}=0.001) .93 .2 \%$ of donors had no previous history of such attack (Table-I \& II).

Table-III

Distribution of clinical character of VVR among the whole blood donors.

\begin{tabular}{llcc}
\hline & Reaction type & Frequency & Percent \\
\hline Grade 1 & Anxiety & 12 & 16.4 \\
& Increased rate of & 22 & 30.1 \\
& respiration & & \\
& Pallor & 49 & 67.1 \\
& Sweating & 26 & 86.3 \\
& Dizziness & 29 & 39.7 \\
& Nausea Vomiting & 59 & 80.8 \\
& Vertigo & 1 & 1.4 \\
Grade 2 & Loss of consciousness & 27 & 37.0 \\
& and falling(fainting) a & & \\
& slow pulse & & \\
\hline
\end{tabular}

Multiple responses

Table-IV

Distribution of blood pressure before and after donation among the whole blood donors.

\begin{tabular}{lcc}
\hline & Mean \pm SD & Range \\
\hline $\begin{array}{l}\text { Systolic blood pressure at } \\
\text { before donation }\end{array}$ & $116.99 \pm 9.38$ & $90-140$ \\
$\begin{array}{l}\text { Diastolic blood pressure at } \\
\text { before donation }\end{array}$ & $77.81 \pm 5.07$ & $70-90$ \\
$\begin{array}{l}\text { Systolic blood pressure at } \\
\text { after donation }\end{array}$ & $91.23 \pm 14.23$ & $60-120$ \\
$\begin{array}{l}\text { Diastolic blood pressure at } \\
\text { after donation }\end{array}$ & $59.73 \pm 10.80$ & $30-80$ \\
\hline
\end{tabular}


Table-V

Distribution of grade of reaction with basal characteristics of blood donors.

\begin{tabular}{lrrr}
\hline \multirow{2}{*}{ Body weight (in kg) } & \multicolumn{2}{c}{ Grade } & P-value* \\
\cline { 2 - 3 } & Grade 1 & Grade 2 & \\
\hline$\leq 60(\mathrm{n}=61)$ & $40(65.6)^{\#}$ & $21(34.4)$ & 0.341 \\
$>60(\mathrm{n}=12)$ & $6(50.0)$ & $6(50.0)$ & \\
Age & & &
\end{tabular}

Age (in years)

$\begin{array}{lccc}\leq 25(\mathrm{n}=33) & 21(63.6)^{\#} & 12(36.4) & 0.167 \\ 25-35(\mathrm{n}=26) & 19(73.1) & 7(26.9) & \\ >35(\mathrm{n}=14) & 6(42.9) & 8(57.1) & \\ \text { Sex } & & & \\ \text { Male }(\mathrm{n}=57) & 36(63.2)^{\#} & 21(36.8) & 0.307 \\ \text { Female }(\mathrm{n}=16) & 10(62.5) & 6(37.5) & \end{array}$

Light meal 4 hours before donation

$\begin{array}{lccc}\text { Yes }(\mathrm{n}=61) & 40(65.6)^{\#} & 21(34.4) & 0.341 \\ \text { No }(\mathrm{n}=12) & 6(50.0) & 6(50.0) & \end{array}$

Number of blood donation

\begin{tabular}{lccc} 
First $(\mathrm{n}=51)$ & $33(64.7)^{\#}$ & $18(35.3)$ & 0.648 \\
Multiple $(\mathrm{n}=22)$ & $13(59.1)$ & $9(40.9)$ & \\
\hline
\end{tabular}

*Chi-square test was done to measure the level of significance. \#Figure within parentheses indicates in percentage.

Presented symptoms were anxiety (16.4\%), tachypnea (30.1\%), Pallor (67.1\%), Sweating (86.3\%), Dizziness (39.7\%), Nausea or vomiting (80.8\%), Vertigo (1.4\%), Loss of consciousness and falling (fainting) (37.0\%) (Table-III). Mean systolic blood pressure at before donation was $116.99 \pm 9.38 \mathrm{~mm}$ of $\mathrm{Hg}$, ranging from 90 to 140, mean diastolic blood pressure at before donation was $77.81 \pm$ 5.07, ranging from 70 to $90 \mathrm{~mm}$ of $\mathrm{Hg}$, mean Systolic blood pressure at after donation was $91.232 \pm 14.23$, ranging from 60 to 120 , mean diastolic blood pressure at after donation was $59.73 \pm 10.80$, ranging from 30 to $80 \mathrm{~mm} \mathrm{Hg}$ (Table-IV). Among donors with body weight $=60 \mathrm{~kg}$, grade 1 reaction was experienced in 56.6\% and grade 2 reaction in $34.4 \%$, among donors with body weight $>60 \mathrm{~kg}$, grade 1 reaction and grade 2 reaction was experienced in equal $50.0 \%$ cases. In age group 25.30 years, grade 1 reaction was experienced in $63.6 \%$ and grade 2 reactions in $36.4 \%$, in age group 30 to 35 years, grade 1 reaction was experienced in $73.1 \%$ and grade 2 reaction in $26.9 \%$, in age group 35-40 years, grade 1 reaction was experienced in
42.9\% and grade 2 reaction in 57.1\%. Among male donors grade 1 reaction was experienced in $63.2 \%$ and grade 2 reactions in $36.8 \%$, among female donors grade 1 reaction $62.5 \%$ and grade 2 reactions was experienced in 37.5\% cases. Among light meal donors grade 1 reaction was experienced in $65.6 \%$ and grade 2 reactions in $34.4 \%$, among non-light meal donors grade 1 and grade 2 reactions was experienced in equal $50.0 \%$ cases. In new donor group grade 1 reaction was experienced in $64.7 \%$ and grade 2 reactions in $35.3 \%$, among donors with history of donation grade 1 reaction $59.1 \%$ and grade 2 reactions was experienced in $40.9 \%$ cases (Table-V).

\section{Discussion:}

In Bangladesh the annual demand for blood transfusion is estimated to be 2,00,000 to 2,50,000 unit per year . But due to lack of voluntary donor and consciousness among people this demand is hardly met ${ }^{3}$. As donor safety is an essential prerequisite for an adequate and safe voluntary blood supply current study was carried out to evaluate the incidence of vaso-vagal reaction following whole blood transfusion. We analyzed clinical records of 19553 whole blood donors over a period of 12 months in the blood bank of BSMMU, Dhaka, Bangladesh.

In the current study the incidence of Vaso-vagal reaction was $0.37 \%$, which is much smaller than the previous reports $(2-3 \%)^{6}, 5.3 \%^{9}, 0.89 \%{ }^{12}$. Our result is closer to Zervou et al $10(0.53 \%)$. We believe that the most possible explanation for this difference is the fact that the physical examination and selection of blood donors is performed by experienced physicians and therefore we take a better evaluation of blood donors who have predisposition to complication. An additional reason for this difference is possibly the small number of donors in study. Although Crocco and D'Elia reported a much smaller incidence of $\operatorname{VVR}(0.2 \%)^{5}$.

The mean of the age was $27.63 \pm 6.29$ years, ranging from 18 to 40 years. Newman and Graves (2001) showed that donors with reactions were more likely to be young than those from the general donor population (median age, 28 vs. 42 years $)^{11}$. The incidence of VVR with respect to donation types, sex and ages was evaluated by Nakajima ${ }^{12}$. The incidence was significantly higher for donors aged 16 to 29 than for donors who are older for both sexes and all donation types ${ }^{12}$. In our study Female donors had a statistically significant higher rate of VVR, which supports findings of previous studies 13-15. On the other hand many other authors reported that there is no significant difference between men and women donors for VVR ${ }^{16-18}$. 
We found that $71.2 \%$ of donors suffered with VVR were new donor and $28.8 \%$ were repeat donor. Wiltbank et al, ${ }^{19}$ Zervou et al, ${ }^{10}$ Newman et al, ${ }^{9}$ and Ogata et al, 20 documented the higher rate of VVR in first time donors than repeat donors. Presented symptoms were anxiety (16.4\%), tachypnea (30.1\%), Pallor (67.1\%), Sweating (86.3\%), Dizziness (39.7\%), Nausea or vomiting (80.8\%), Vertigo (1.4\%), Loss of consciousness and falling (fainting) (37.0\%) (Table III). Reported symptoms by Zervou et al ${ }^{10}$ in order of frequency were Weakness (64\%), sweating (47.6\%), pallor (38.2\%), headache (14\%), dizziness (11.2\%) and nausea ( $8.4 \%$ ) were the most common symptoms. Loss of consciousness occurred in 22 cases (20.5\%). In Newman series Pallor (87\%), dizziness (67\%), diaphoresis (49\%), hyperventilation (49\%), and nausea (25\%) were the five most common clinical findings before syncope. Approximately one quarter of the donors with nausea, or 6 percent of all donors with syncope, experienced emesis ${ }^{11}$. Characteristics of reaction (grade 1 or grade 2 ) was not significantly different according to age, sex, body weight, first time donor or repeat donor and history of taking light meal before donation.

\section{Conclusion:}

Although the incidence of vaso-vagal reaction is relatively smaller in our study, considering the latent risk of vasovagal reaction we should ensure the careful selection and evaluation of blood donors by experienced physicians and the presence of trained nurses in the donation room who closely attend the blood donors during and immediately after blood donation.

\section{References:}

1. Riley W, Schwei M, McCullough J. 'The United States' potential blood donor pool: the prevalence of donor-exclusion factors on the pool of potential donors', Transfusion. Vol. 47, no. 7, pp. 1180-1188, 2007,

2. Rohit S. 'South East Asia faces sever shortage of safe blood', BMJ. Vol. 320, No. 7241, p. 1026, 2000.

3. Government of Bangladesh and UNDP: Directorate General of Health Services, Ministry of Health and Family welfare. Safe blood transfusion. Safe blood transfusion programme Bangladesh.

4. Callero PL and Piliavin JA. 'developing a commitment to blood donation: the impact of one's first experience', J Appl assoc. Psychology. Vol. 13, pp. 1-16, 1983.

5. Crocco A and D' Elia D. 'Adverse reactions during voluntary donation of blood and/or blood components. A statisticalepidemiological study', Blood Transfus.vol. vol.5, pp. 143152, 2007.
6. Newman BH. 'Donor reactions and injuries from whole blood donation’, Transfus Med Rev. Vol.11, pp. 64-75, 1997.

7. Newman B, Tommolino E, Andreozzi C, Joychan S, Pocedic J, Heringhausen J: The effect of a 473-ml (16-oz) water drink on vasovagal donor reaction rates in high-school students. Transfusion 2007; 47:1524-1533.

8. Boynton MH, Taylor ES. 'Complications arising in donors in a mass blood procurement project', Am J Med Sci. Vol. 209, pp.421-36, 1945.

9. Newman BH, Shawn Pichette, Dena Pichette, and Ema Dzaka, 'Adverse effects in blood donors after whole-blood donation: a study of 1000 blood donors interviewed 3 weeks after wholeblood donation', TRANSFUSION. Vol, 43, pp. 598-603, 2003.

10. Zervou EK, K. Ziciadis, F. Karabini, E. Xanthi, E. Chrisostomou and A. Tzolou. 'Vasovagal reactions in blood donors during or immediately after blood donation', Transfusion Medicine, Vol. 15, pp. 389-394, 2005,

11. Newman BH, Graves S. 'A study of 178 consecutive vasovagal syncopal reactions from the perspective of safety', Transfusion. Vol. 41, pp. 1475-9, 2001.

12. Nakajima K. 'Donor complications and donor care', ISBT Science Series. Vol. 4, pp. 411-417, 2009.

13. Trouern-Trend JJ, Cable RG, Badon SJ, Newman BH, Popovsky MA. 'A case-controlled study of vasovagal reactions in blood donors. Influence of sex, age, donation status,weight, blood pressure, and pulse', Transfusion. Vol. 39, pp. 316-20, 1999.

14. Newman BH. 'Vasovagal reactions in high school students: findings relative to race, risk factor synergism, female sex, and non-high school participants', Transfusion. Vol. 42, pp. 1557-60, 2002.

15. Kasprisin DO, Glynn SH, Taylor F, Miller KA. 'Moderate and severe reactions in blood donors', Transfusion. Vol. 32, pp. 23-6, 1992.

16. Popovsky MA, Whitaker B, Arnold NL. 'Severe outcomes of allogeneic and autologous blood donation: frequency and characterization’, Transfusion. Vol. 35, pp.734-7, 1995.

17. Tomasulo PA, Anderson AJ, Paluso MB, et al. 'A study of criteria for blood donor deferral', Transfusion. Vol. 20, pp. 511-8, 1980.

18. Smith ML, Hudson DL, Raven PB. 'Effect of muscle tension on the cardiovascular responses to lower body negative pressure in man', Med Sci Sports Exerc Vol. 19, pp. 436-42, 1987.

19. Wiltbank TB, Giordano GF, Kamel H, Tomasulo P, Custer B 'Faint and prefaint reactions in whole-blood donors', Transfusion. Vol. 48, pp, 1799-1808, 2008.

20. Ogata H, Iinuma N, Nagashima K and Akabane T. 'Vasovagal reactions in blood donors', Transfusion. Vol. 20, N0. 6, pp. 679 - 683, 2003. 